\title{
D-Wave Characteristics due to Inter Atomic Nature of Superconductors
}

\author{
P. Antony Lyla, R.Suganya, K.Sathiyamurthy
}

\begin{abstract}
The superconductivity of the compound materials lives in the $\mathrm{BaO}$ layers. This superconductivity is s-wave, not d-wave, in the size. The trio of ruthenatemixes, doped Sr2YRuO6, $\mathrm{GdSr} 2 \mathrm{Cu} 2 \mathrm{RuO}$, and $\mathrm{Gd} 2-\mathrm{CezSr} 2 \mathrm{Cu} 2 \mathrm{RuO} 10$ all superconductors in their $\mathrm{SrO}$ layers. It is exhibited that the happening of superconductivity in UPd2Al3 can be comprehended inside of the twofold model for $5 f$ electrons. Because of intense intra-nuclear or Hund's guideline relationships two of the $5 f$ electrons stay restricted as the remaining some portion of $5 f$ is delocalized and part of the conduction electrons. Cooper-pair development of the last happens because of the swap of attractive excitations inside of the limited $5 f$ subsystem.
\end{abstract}

Keywords :atoms,acitinide,waveselectron,conductivity.

\section{INTRODUCTION}

We consider extraordinary earth dirtying impacts with crystalline electric field (CEF) split imperativeness levels and study their result on a superconducting grid. [1],[3],[5] By [4], the distinctive interchanges between conduction electrons and such contaminating impacts can be classified with significance their change properties underneath insurgencies and turn turns. He exhibited that their total arrangement is a few $(2 m+1)$ and counterparts fourteen, as an eventual outcome of for $\mathrm{f}$ electrons $\mathrm{m}=$ three. Among them, the isotropous Coulomb joint effort is of no diversion. the superior crucial associations square measure the isotropic exchange coordinated effort and therefore the a round Coulomb charge scrambling. Kinder the previous $\}$ is created in the structure [32],[34]

The Illinois staff have appreciated their comments as affirmation of d-wave electrical conduction within the priest planes. Anyway this interpretation is predicated completely on the convictions that (I) they acknowledge that the clergyman planes super lead, and (ii) Janus-stood up to with the genuine reality that their understanding don't

Revised Manuscript Received on July 22, 2019

P.Antony Lyla Department of Physics, Bharath Institute of Higher Education and Research, Chennai, India. Email: lylalenin@gmail.com

R.Suganya, Department, Department of Physics, Bharath Institute of Higher education and Research, Chennai, India. Email: suganya_s_r@yahoo.com

K.Sathiyamurthy, Department of Physics, Bharath Institute of Highe Education and Research, Chennai, India. Email: gksathiya0806@gmail.com demonstrate the typical U-shape (with a chiseller $U$ than BiO's foreseen for s-wave superconductivity), they expect that they require check of $\mathrm{d}$-wave electrical conduction $\mathbf{C}$. Rajeevgandhi,

However the work of Klemm [3] and Li [2] give a convincing show that the electrical conduction in $\mathrm{Bi} 2 \mathrm{Sr} 2 \mathrm{CaCu} 2 \mathrm{O} 8$ is s-wave in character, and that we have discovered [8], exploitation the larger part test of lepton subjective investigation, that the electrical conduction of $\mathrm{YBa} 2 \mathrm{Cu} 3 \mathrm{O} 7$ is moreover s-wave in character with A vulnerability of yet $4 \times 10-6$. it's passing impossible that, inside of the mass, $\mathrm{YBa} 2 \mathrm{Cu} 3 \mathrm{O} 7$ may have s-wave matching, while $\mathrm{Bi} 2 \mathrm{Sr} 2 \mathrm{CaCu} 2 \mathrm{O} 8$ has d-wave [4] (which cannot be meek with various estimations [9]). Thusly the higher illumination of the actualities in regards to the $\mathrm{CuO} 2$ layers of the Illinois group is that they include a band-hole inside the $\mathrm{CuO} 2$ layers, and individual layers don't start electrical conduction[2 ], [ 4],[6]

\section{MATERIALS AMD METHODS}

Actinide particles may have vagrant furthermore as limited $5 \mathrm{f}$ electrons. There should be either 2 or three $5 \mathrm{f}$ electrons at a site, therell only one of them bouncing from \{site| website| web website $\}$ to webpage. The decision of the delocalized orbital, on the inverse hand is chosen by intra-nuclear relationships. it is important to notice that the vitality increase attributable to numerous arrangements surpass the one got from the KEFor jumping to happen, one site should be involved by three $f f$ electrons (site a), while there square measure 2 at the other site $b$. we have a tendency to accept that the starting state locally stasesHund's standards, i.e., the $5 \mathrm{f}$ shells square measure in their particular ground states. Exchanging a $5 \mathrm{f}$ lepton from \{site|website/web. website $\}$ ato webpage b can commonly bring about a final state wherever both i.e., the remaining doubly possessed $5 \mathrm{f}$ shell at site/website|web. website $\}$ too bad well in light of the fact that the triply involved $5 \mathrm{f}$ shell at website b square measure in energized state

Contingent upon the principal state, Hund's rule can be safeguarded just for specific symmetries of the exchanged orbital. The Superconductivity through Intra-Atomic Excitations. Solid confirmation for an exchange of $\mathrm{CEF}$ excitations 
superconductivity originates from burrowing

[23] and inelastic neutron dissipating tests [19-22,28].. The deliberate attractive excitation vitality at the antiferromagnetic zone focus Q0 is somewhat more noteworthy than $2 \Delta=6 \mathrm{TC}$ and results in detectable reverberation structures when superconductivity sets in [28].For a predictable depiction of superconductivity and the upgraded powerful mass, a model estimation has been performed in Ref. [6] that uses a fit of the three-dimensional attractive exaction scattering imitative from inelastic neutron scrambling. The scattering is most purported in the c-bearing and we should [7],[9],[11]

The Fermi surface of the underground bug ferromagnetic ground state involves a barrel formed half and a torus(see Fig. 4). within the magnet express, every sheets result from a similar band. For straightforwardness we will do the calculations for a magnet state and assessed the Fermi surface by a slight wrinkled chamber. The latter is addressed by a logical dispersing. [31],[33],[35]

This shows up value in context of the very reality that AF solicitation opens little openings at the relating symmetry centers that have a likewise little impudence on the superconducting move temperature $\mathrm{T}$. This was considered before on systems, for example, blends an area unit done, assurance the Eliashberg scientific articulations decreases to a one-dimensional issue. the resulting purpose behind existing is vital and should be centered around: the bit $\mathrm{K}(\mathrm{q}, \omega)$ is adequately peaked at $\mathrm{qz}=\mathrm{p} / \mathrm{c}$ and $\omega \mathrm{vv}=$ zero. Along these lines, for the most part talking, for the clothing channel the hole numerical articulation is of the type6] [8],[ 10] ,[12]
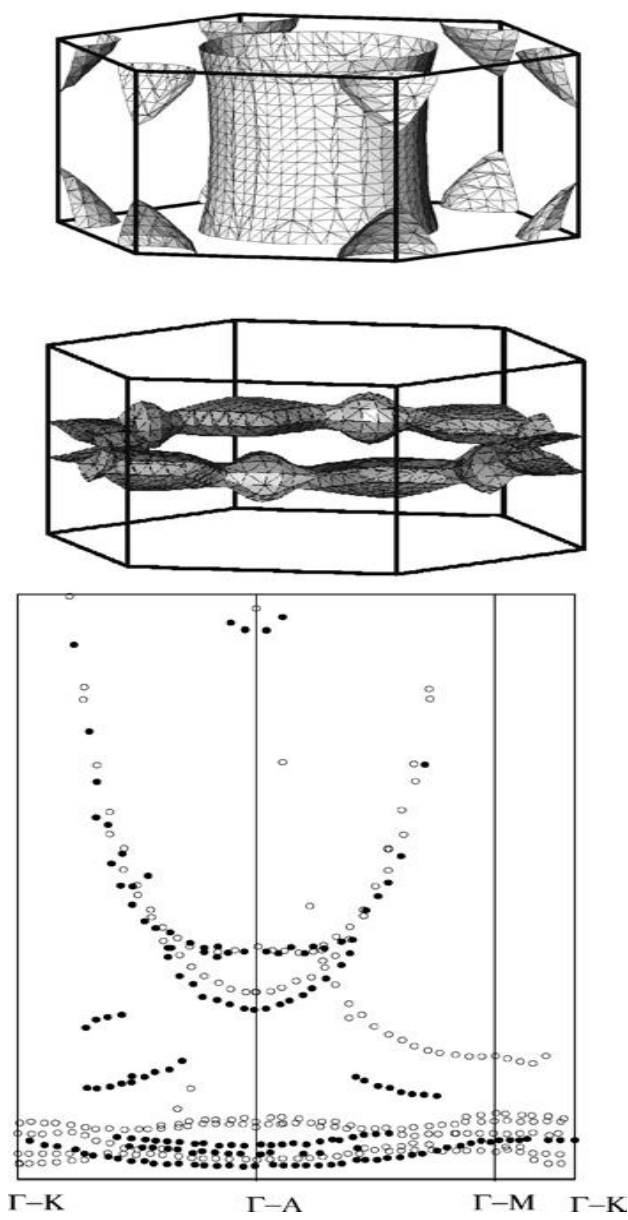

Figure 1 -Upper panel:Fermi surface of UPd2Al3 computed inside of the double approach. The fundamental chamber part has likewise an overwhelming mass with $\mathrm{m}=$ 19-33 m.

\section{DISCUSSION}

Owing to the sturdy negatron correlations and therefore the slender energy bands, the Fermi velocity becomes little, and therefore the coherence length $\mathrm{j}$ becomes short. [26],[28],[30]

The short coherence length results in a clean kind II super conductors, whereas the tiny Fermi rate reduces the orbital pair-breaking result and results

in a high higher crucial [3].it's conjointly renowned that propert $y$ of the gap enhances the FFLO electrical conduction [4-6]. Besides, the quasi-low-dimensionality conjointly favors the FFLO state: property of the Fermi surface (FS) enhances the FFLO electrical onduction [5,7,10], whereas the orbital pair-breaking result is suppressed by applying the magnetic flux in a very direction parallel to the extremely conducting layer $[8,9]$. Thus, we tend to contemplate that the FFLO state in QLD exotic superconductors is a crucial subject to be studied. On the opposite hand, we've got some experimental facts in organics that may counsel the FFLO state in these compounds. as an example, extraordinarily high upper crucial fields in parallel directions have been observed in several of the quasi-one-dimensional(Q1D) and quasi-two-dimensional (Q2D) organic superconductors [11]. [13], [15] ,[ 17]

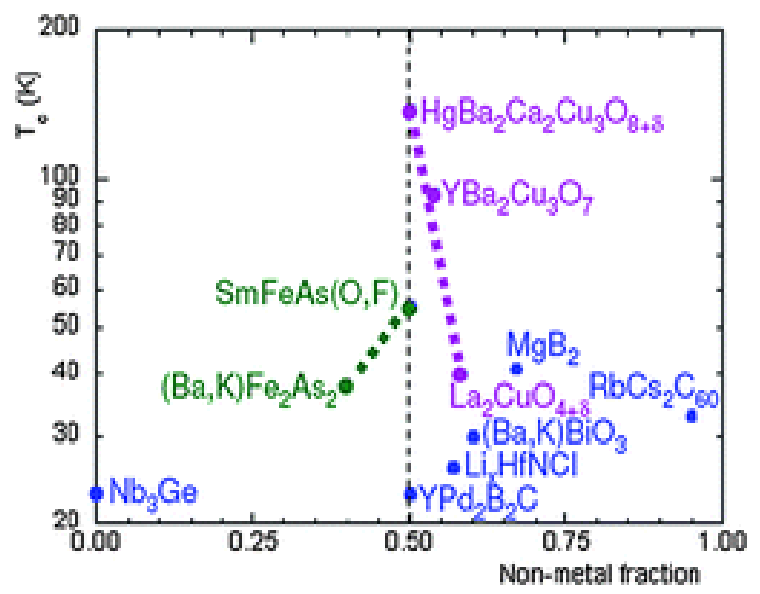

We have a few competitors of the component of such exceptional increment of the significant field, similar to turn triplet matching, turn circle coupling, strong coupling result, transformation result, the FFLO state, etc. The triplet matching could be a characteristic clarification of the higher than exploratory certainties, and is upheld in (TMTSF) $2 \mathrm{ClOby}$ a warm conductivity analyze [7]. For the triplet matching instrument, be that as it may, we ought to consistently have a recuperation of the change 4 temperature of the electrical conduction at horribly high attractive fields 
[9], anyway such conduct has not experienced an investigation affirmed in any case. Inside the turn singlet blending, the FFLO state is perhaps the principal characteristic component from subjective and quantitative perspectives. Notwithstanding, we will in general don't have any immediate proof of the FFLO state at the current. Inside the future, for instance, perception of the extraordinary structures of the superconducting request parameter by a filtering burrowing magnifier (STM) tests is an immediate proof of presence or nonbeing of the FFLOstate. Accordingly, it's important to foresee the extraordinary structure of the FFLO state on paper [19],[21],[23]

\section{CONCLUSION}

Taking into account the twin model for $5 f$ electrons in $\mathrm{U}$ exacerbates our infinitesimal comprehension of those materials has by and large advanced. UPd2Al3is a model case for that. Not exclusively will the solid anisotropy of the semi-liberal quantum mass be clarified while not versatile parameter, at any rate conjointly the scope of the superconducting move temperature is picked up in sharp check. The last is made by the trading of intra-nuclear excitations between the conductivity electrons accomplishing Cooper-pair game-plan. The intra-nuclear excitations occur inside the game-plan of compelled 5 f electrons. They shape a band of charming excitations that has been inquired about and depicted by non-versatile nucleon dispersing. [20],[22], [24]

An extraordinary piece of the time the exchanging of engaging excitations between conductivity electrons is have a go at breaking. Here it's pair-limiting as we've shown incredibly well. [25],[27],[29]

Regardless, this needs a superconducting request parameter which contains a line of focus focuses inside the polygon plane. Anode structure of this sort was beginning late watched likely by taking ahead of the pack of the anisotropic warm physical miracle molecule charming fields. In this way, the signs region unit sound thatUPd $2 \mathrm{Al} 3$ is when in doubt a superconductor with a non-photonic participation being the explanation for movement. [14],[ 16], [18]

\section{REFERENCES}

1. Nageshwari M., Jayaprakash P., Kumari C.R.T., Vinitha G., Caroline M.L., Growth, spectral, linear and nonlinear optical characteristics of an efficient semiorganic acentric crystal: L-valinium L-valine chloride, 2017, Physica B: Condensed Matter, V-511, PP -1-9,

2) Sangeetha P., Jayaprakash P., Nageshwari M., Rathika Thaya Kumari C., Sudha S., Prakash M., Vinitha G., Lydia Caroline M., Growth and characterization of an efficient new NLO single crystal L-phenylalanine D-methionine for frequency conversion and optoelectronic applications, 2017, Physica B: Condensed Matter, V-525, PP-164-174

3) Peer Mohamed M., Jayaprakash P., Nageshwari M., Rathika Thaya Kumari C., Sangeetha P., Sudha S., Mani G., Lydia Caroline M., Crystal growth, structural, spectral, thermal, linear and nonlinear optical characterization of a new organic nonlinear chiral compound: L-tryptophan-fumaric acid-water (1/1/1) suitable for laser frequency conversion, 2017, Journal of Molecular Structure, V-1141, PP-551-562

4) Jayaprakash P., Sangeetha P., Kumari C.R.T., Caroline M.L., Investigation on the growth, spectral, lifetime, mechanical analysis and third-order nonlinear optical studies of L-methionine admixtured D-mandelic acid single crystal: A promising material for nonlinear optical applications, 2017, Physica B: Condensed Matter, V-518, PP-1-12

5) Nageshwari M., Kumari C.R.T., Vinitha G., Mohamed M.P., Sudha S., Caroline M.L., Crystal growth, structural, spectral, thermal, dielectric, linear and nonlinear optical characteristics of a new organic acentric material: L-Methionine-Succinic acid (2/1), 2018, Journal of Molecular Structure, V-1155, PP-101-109

6) Jayaprakash P., Sangeetha P., Kumari C.R.T., Baskaran I., Caroline M.L., Growth and characterization of 1-asparagine monohydrate admixtured dl-mandelic acid nonlinear optical single crystal, 2017, Journal of Materials Science: Materials in Electronics, V-28, PP-18787-18794

7) Rathika Thaya Kumari C., Nageshwari M., Jayaprakash P., Sangeetha P., Sudha S., Lydia Caroline M., Investigation on growth, optical, thermal, mechanical, dielectric, LDT studies of sulphanilic acid monohydrate: A promising third-order nonlinear optical material, 2017, Journal of Nonlinear Optical Physics and Materials, V-26, I - 2 ,

8) Thaya Kumari C.R., Nageshwari M., Raman R.G., Caroline M.L., Crystal growth, spectroscopic, DFT computational and third harmonic generation studies of nicotinic acid, 2018, Journal of Molecular Structure, V-1163, PP-137-146

9) Nageshwari M., Kumari C.R.T., Sangeetha P., Vinitha G., Caroline M.L., Third order nonlinear optical, spectral, dielectric, laser damage threshold, and photo luminescence characteristics of an efficacious semiorganic acentric crystal: L-Ornithine monohydrochloride, 2018, Chinese Journal of Physics, V-56, I - 2, PP-502-519

10) Kumari C.R.T., Jayaprakash P., Nageshwari M., Mohamed M.P. Sangeetha P., Caroline M.L., Growth, optical, photoluminescence, dielectric, second and third order nonlinear optical studies of benzoyl valine acentric crystal, 2017, Molecular Crystals and Liquid Crystals, V-658,I - 1, PP-186-197

11) Rathika Thaya Kumari C., Nageshwari M., Sudha S., Lydia Caroline M., Mani G., Influence of uranyl on the growth, linear, laser damage threshold and nonlinear optical studies on potential nonlinear optical single crystal: L-Alanine, 2015, Journal of Chemical and Pharmaceutical Sciences, V-2015-October,PP-166-170,

12) Rathika Thaya Kumari C., The detailed study ontwo dimensional hydrogen atom, 2013, Middle - East Journal of Scientific Research, V-17,I-12, PP-1900-1902

13) Rathika Thaya Kumari C., Theoretical study about the measurement of ultrasonic velocity using different methods, 2013, Middle - East Journal of Scientific Research, V-17, PP-12-

14) Mukunthan A., Rathika Thaya Kumari C., Nageshwari M., Prakash D., The effect of super saturation and crystal growth kinetics of L-arginine per chlorate, 2013, Middle - East Journal of Scientific Research, V-17,I-12 PP-1825-1827

15) Sree Latha R., Vijayaraj R., Azhagiya Singam E.R., Chitra K., Subramanian V., 3D-QSAR and Docking Studies on the HEPT Derivatives of HIV-1 Reverse Transcriptase, 2011, Chemical Biology and Drug Design, V-78,I-12, PP-1816-1819

16) Sree Latha R., Vijayaraj R., Padmanabhan J., Azhagiya Singam E.R., Chitra K., Subramanian V., 3D-QSAR studies on the biological activity of juvenile hormone mimetic compounds for Culex pipiens Larvae, 2013, Medicinal Chemistry Research, V-22, I-12,PP-418-426

17) Subashini G.,A simple proof on coloring of dominated special graphs, Indian Journal of Science and Technology,V-7,I-,PP-5-6,Y-2014

18) Ramya N.,On coloring of corona graphs, Indian Journal of Science and Technology,V-7,I-SUPPL2,PP-9-11,Y-2014.

19) Ramya N., On colourings of wheel graph (Wn), Indian Journal of Science and Technology,V-7,I-,PP-72-73,Y-2014

20) Ramya N., On star chromatic number of P3 (n), Indian Journal of Science and Technology,V-7,I-,PP-7-8,Y-2014.

21) Vijayaragavan S.P.,An investigative expert that's general FBG sensors,International Journal of Mechanical Engineering and Technology,V-8,I-8,PP-1500-1505,Y-2017

22) Vijayaragavan S.P.,Equalization routing protocol for $\mathrm{Wi}-\mathrm{Fi}$ sensor strategy,International Journal of Mechanical Engineering and Technology,V-8,I-8,PP-1662-1666,Y-2017

23) Karthik B., Kiran Kumar T.V.U., Vijayaragavan P., Bharath Kumaran E.,Design of a digital PLL using 0.35 ̂ิ1/4m CMOS technology,Middle East Journal of Scientific Research,V-18,I-12,PP-1803-1806,Y-2013

24) Kanniga E., Selvaramarathnam K., Sundararajan M.,Kandigital bike operating system,Middle - East Journal of Scientific Research,V

25) Jasmin M., Vigneshwaran T., Beulah Hemalatha S.,Design of power aware on chip embedded memory based FSM encoding in FPGA,International Journal of Applied Engineering 
Research,V-10,I-2,PP-4487-4496,Y-2015

26) Jasmin M.,Optimization techniques for low power VLSI circuits,Middle - East Journal of Scientific Research,V-20,I-9,PP-1082-1087,Y-2014

27) Jasmin M., Vigneswaran T.,Fuzzy controller for error control of on Chip communication,2017 International Conference on Algorithms, Methodology, Models and Applications in Emerging Technologies, ICAMMAET 2017,V-2017-January,I-,PP-1-5,Y-2017

28) Ramya N., On star chromatic number of $P 3$ (n),Indian Journal of Science and Technology,V-7,I-,PP-7-8,Y-2014.

29) Cauchy Multiplication of Euler Summable series in Ultrametric Fields, PNNVS R.Deepa Commentationes Mathematicae 53 ((1)), 73 - 79

30) Kumaravel A., Meetei O.N.,An application of non-uniform cellular automata for efficient cryptography,Indian Journal of Science and Technology,V-6,I-SUPPL5,PP-4560-4566,Y-2013

31) Kumaravel A., Meetei O.N.,An application of non-uniform cellular automata for efficient cryptography,2013 IEEE Conference on Information and Communication Technologies, ICT 2013,V-,I-,PP-1200-1205,Y-2013

32) Kumarave A., Rangarajan K.,Routing alogrithm over semi-regular tessellations,2013 IEEE Conference on Information and Communication Technologies, ICT 2013,V-,I-,PP-1180-1184,Y-2013

33) Gopinath S., Sundararaj M., Elangovan S., Rathakrishnan E.,Mixing characteristics of elliptical and rectangular subsonic jets with swirling co-flow,International Journal of Turbo and Jet Engines,V-32,I-1,PP-73-83,Y-2015

34) Rathika Thaya Kumari C., A brief review on the impacts of tropospheric ozone on biological systems, 2013, Middle - East Journal of Scientific Research, V-17,I-12, PP-1820-1824

35) Mukunthan A., Rathika Thaya Kumari C., Nageshwari M., Prakash D., A brief review on the applications of fluorescent spectroscopy in biomedical diagnosis, 2013, Middle - East Journal of Scientific Research, V-17,I-12, PP-1828-1830

\section{AUTHORS PROFILE}

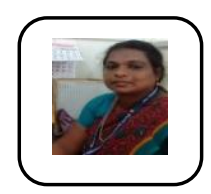

P.Antony Lyla, Assistant Professor, Department of Physics, Bharath Institute of Higher Education and Research, Chennai, India

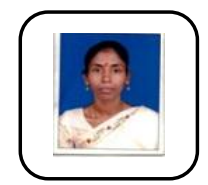

R.Suganya, Assistant Professor, Department of Physics, Bharath Institute of Higher Education and Research, Chennai, India

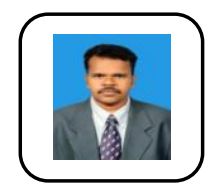

K.Sathiyamurthy Assistant Professor, Department of Physics, Bharath Institute of Higher Education and Research, Chennai, India 